\title{
Cyclical iron supplementation to reduce anemia among Brazilian preschoolers: a randomized controlled trial
}

\author{
Geraldo GPL Coutinho ${ }^{1,4^{*}}$, Patrícia M Cury ${ }^{2}$ and José A Cordeiro ${ }^{3}$
}

\begin{abstract}
Background: Iron-deficiency anemia is the most common type of nutritional disorder. New strategies for the treatment of anemia are very important for its reduction. The aim of this study was to assess the efficacy and feasibility of cyclical iron supplementation as a strategy to reduce the prevalence of anemia among preschoolers.

Methods: A randomized controlled trial was performed in the entire population of under five-year-old children who attended government daycare centers in a small town in the State of Sao Paulo, Brazil. The children were randomly allocated into two intervention groups: the Weekly and Cyclical Groups. During a ten-month period, the Weekly Group ( $n=51)$ received weekly doses of $30 \mathrm{mg}$ elemental iron (40 doses) and the Cyclical Group ( $n=48)$ received two cycles of 20 daily doses of $30 \mathrm{mg}$ elemental iron separated by a four-month period (40 doses).

Results: Overall, at the end of ten months, the prevalence of anemia of the children on both supplementation regimens showed a significant decrease from 20.20\% to 5.05\% ( $p$-value $<0.0005$ ). There was no significant difference in the anemia between the two groups ( $p$-value $=0.35$ ). The mean hemoglobin concentration increased by $0.27 \mathrm{~g} / \mathrm{dL}$ (p-value $<0.016$ ) and $0.47 \mathrm{~g} / \mathrm{dL}$ ( $\mathrm{p}$-value < 0.0005 ) in the Weekly and Cyclical Groups, respectively; again there was no significant difference between groups ( $p$-value $=0.17$ ). However, the cyclical regimen was easier to manage.

Conclusions: Both supplementation regimens significantly reduced the prevalence of anemia however administration of the Cyclical Group was easier to carry out and control.
\end{abstract}

Clinical trial registration number: NCT00992823

Keywords: Iron, Anemia, Supplementation, Brazil, Preschoolers

\section{Background}

Iron-deficiency anemia is the most common type of nutritional disorder. It affects populations around the entire World but in particular those of poorer communities in developing countries [1]. The two most vulnerable groups are preschool children and pregnant women [1]. While anemia is recognized as a serious public health problem worldwide, its prevalence remains at unacceptably high levels [2]. Although there are few recent data on the prevalence of anemia in Brazil, studies in the State of Sao

\footnotetext{
* Correspondence: gegac@terra.com.br

'Department of Post graduation, School of Medicine, São José do Rio Preto, São Paulo 15090-000, Brazil

${ }^{4}$ Departamento de pós-graduação, Faculdade de Medicina de São José do Rio Preto, Av. Brigadeiro Faria Lima, 5416 ZIP 15090-000, São José do Rio Preto, SP, Brazil

Full list of author information is available at the end of the article
}

Paulo report prevalences of between 30\% and 69\% depending on the type of community studied [3-5].

Guidelines for treating preschoolers, as presented by the United Nations Administrative Committee on Coordination/Sub-Committee on Nutrition (ACC/ASN) [6], recommend supplementation in daily doses of elemental iron for two to three weeks several times each year. Thus, this guideline is vague as although the regimen should be repeated 'several times each year', the ideal interval between supplementations is not defined. The result is that some health departments repeat the regimen too few times and others too many thereby reducing the efficiency of supplementation and wasting resources.

A second strategy is based on the renewal rate of the human intestinal mucosa (seven days) suggesting that it is

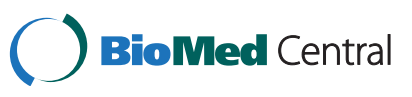


possible to reduce anemia with weekly supplementation of iron. According to some studies this is as efficacious as daily supplementation in reducing the prevalence of anemia [7-9] although Engstrom et al. found that this is not be the case in 6- to 12-month-old infants [10]. Even so this regimen requires careful administration as missed doses should be replaced on the following day, a situation that is difficult to control.

As anemia is highly prevalent among children of developing countries including Brazil [11-13] and because of the negative effects of anemia on psychomotor development [14] different strategies should be investigated in order to reduce non-compliance to treatment.

The aim of this study was to assess the efficacy and feasibility of cyclical iron supplementation with the interval between supplementations being based on the mean life of red blood cells of approximately 120 days [15].

\section{Methods}

This was a randomized controlled trial involving two intervention groups: Weekly and Cyclical Groups based on the type of supplementation.

The design of this study followed the ethical requirements established by Resolution 196/96 of the National Health Council of the Ministry of Health. The Research Ethics Committee of the Medicine School in São José do Rio Preto, Brazil (process \# 0708/2006) approved the study, which was conducted from January 2007 to July 2008, in Bady Bassitt, a town in the State of São Paulo, Brazil.

The town of Bady Bassit was chosen as the setting for this study because of the possibility of enrolling the entire under five-year-old population attending all four government daycare centers in the town and because of the relatively similar background of all the children.

The subjects (252) were 24- to 59-month-old children from four local public daycare centers. All children attended the daycare centers from 7:00 a.m. to 5:00 p.m. and received the same type of food, which was provided by a central kitchen run by the local council. A typical daily diet at school included bread and butter or cheese, milk, biscuits and fruit for breakfast, rice, beans, meat (minced beef, chicken, liver or fish), vegetables and a fruit or jelly for lunch and bread and butter or cheese, biscuits and fruit juice before going home.

Two weeks prior to iron supplementation, all the children in the study had parasitological tests with stool (feces) analysis. Those who presented with infections at the beginning of the intervention, reported any infection within two weeks before the supplementation, presented with hereditary anemia or those who were already taking medication containing ferrous sulfate were excluded from the study.

Thus, of the 252 children who were attending the daycare centers, only 131 parents consented to permit their children participate in the study. Of these 11 were excluded, six due to infections, four were already taking medicines containing ferrous sulfate and one had hereditary anemia.

Hence, iron supplementation was started in 110 anemic and non-anemic children. The children were randomly assigned (table of randomly distributed numbers) to one of two intervention groups with 55 subjects each. Sample size calculations indicated that with $\geq 33$ children per group, it would be possible to detect hemoglobin changes with a power of 0.8 and $\mathrm{p}$-value $=0.05$, considering a prevalence of anemia of around $40 \%$ and a $50 \%$ reduction.

During the study, 11 children left the daycare centers and the study. Thus, the data discussed in this paper is on 99 children that received all the iron doses. Iron supplementation was administered to the children on empty stomachs after they had been playing for a short time so that they better accepted the medication by staff of the daycare centers who also recorded compliance to treatment.

Codes were used to identify bottles of unflavored elemental Fe (ferrous sulfate) oral solution $(30 \mathrm{~mL})$ in both groups. The Fundação Remédio Popular, a laboratory kept by the government of São Paulo State, provided the medication, with one drop containing $1 \mathrm{mg}$ elemental iron.

Children in the Weekly Group received a single $30 \mathrm{mg}$ oral dose (30 drops $-1.5 \mathrm{~mL}$ ) ferrous sulfate using a $2-\mathrm{mL}$ disposable syringe every Wednesday during the ten months of the study. Children in the Cyclical Group received a daily dose of $30 \mathrm{mg}$ of elemental Fe on 20 consecutive school days (one month) repeated after four months without medication.

If a child in the Weekly Group missed a dose due to absence from the daycare center, the missed dose was administered on the day of the child's return to the daycare center. Children in the Cyclical Group who were absent during the supplementation period continued to receive iron upon their return to the daycare center until all 20 scheduled doses had been administered. Therefore, the duration of supplementation (10 months) was the same for both groups and all children received the same number of doses (40).

In order to compare the groups, anthropometric measurements were taken of all children prior to the intervention including weight (weighing scales: scale $50 \mathrm{~g}$ ), height (unstretchable measuring tape: scale $0.1 \mathrm{~cm}$ ) and age. Measurements were made by a single trained nurse. Moreover, venous blood samples were drawn for laboratory tests to quantify the serum hemoglobin of each child at the start and at the end of the experimental period. Hemoglobin concentrations were calculated using a Coulter STKS ${ }^{\circledR}$ device (Coulter Electronics, Inc. Hialeah, Florida U.S.A.) which uses the cyanomethemoglobin method of analysis [16]. 
If a child still presented with anemia at the end of the study, he/she was referred for specialist treatment. Anemia in this age range means hemoglobin concentration levels lower than $11.0 \mathrm{~g} / \mathrm{dL}$ [1].

At the end of the experimental period, the four staff members of the four daycare centers who had administered the medication answered the following question: "In your opinion, which of the two treatments was simpler to administer and why?"

\section{Statistical analysis}

The t-test for paired samples was used to compare means between groups, and the normal approximation test for two ratios or the Fisher's exact test, as recommended, were used to compare event probability in both groups. Statistical analysis was performed using the Minitab computer program version 12.22 (Minitab Inc ${ }^{\circledR}$ ) and the adopted level of significance was $5 \%$ (p-value $<0.05)$.

\section{Results}

The parasitological examinations before the start of supplementation did not detect helminthes in any of the participants.

Data revealed that both groups were comparable in terms of age, height and weight before iron supplementation (p-value $>0.05$ - Table 1) and also in terms of hemoglobin concentration ( $\mathrm{p}$-value $=0.56$ ).

Immediately after receiving the medication, the staff member of the daycare center who administered the iron asked the children if they had experienced any side effects due to the medication (e.g. nausea, stomach pain, diarrhea, constipation). During the experimental period, three children (one in the Weekly Group and two in the Cyclical Group: 3.03\% of the total) suffered from nausea probably due to the medication. However, they remained in the study until the end of the intervention period.

Overall, the percentage of anemic children (hemoglobin $<11.0 \mathrm{~g} / \mathrm{dL}$ ) decreased from $20.20 \%$ at the start of the study to $5.05 \%$ at the end ( $\mathrm{p}$-value $=0.0005)$. The prevalence of anemia in the Weekly Group $(\mathrm{n}=51)$ decreased from $17.65 \%$ to $3.92 \%$ ( $\mathrm{p}$-value $<0.0005$ ) and for the Cyclical Group ( $\mathrm{n}=48)$ the prevalence of anemia decreased from $22.90 \%$ to $6.25 \%$ (p-value $<0.0005$ ). Thus the prevalence of anemia decreased significantly in both groups ( $p$-value

Table 1 Characteristics of the 99 children of the weekly and cyclical groups at the start of the study

\begin{tabular}{lccc}
\hline Characteristic & $\begin{array}{c}\text { Weekly Group } \\
(\mathbf{n}=\mathbf{5 1})\end{array}$ & $\begin{array}{c}\text { Cyclical Group } \\
\mathbf{( n = 4 8 )}\end{array}$ & p-value \\
\hline Mean age - months & $44.44 \pm 9.19$ & $46.53 \pm 10.32$ & 0.30 \\
\hline Weight $-\mathrm{Kg}$ & $16.10 \pm 2.57$ & $16.19 \pm 2.67$ & 0.87 \\
\hline Height $-\mathrm{m}$ & $1.00 \pm 0.07$ & $1.01 \pm 0.08$ & 0.97 \\
\hline Gender - male (\%) & 49.21 & 58.33 & 0.41 \\
\hline
\end{tabular}

Data shown as means \pm standard deviation or percentage.
$<0.0005)$, however the results were not significantly different between groups ( $\mathrm{p}$-value $=0.35$ ).

After 10 months of supplementation, there were statistically significant increases in blood hemoglobin concentrations for both groups (Table 2). An overall increase in the mean hemoglobin concentration of $0.37 \mathrm{~g} / \mathrm{dL}$ was observed ( $\mathrm{p}$-value $=0.001)$.

After 10 months of supplementation, the increases in hemoglobin concentration were not significantly different between the groups ( $p$-value $=0.17$ ). All the staff members of the daycare centers stated that the cyclical regimen was easier in respect to dose administration and treatment management in comparison with weekly supplementation.

\section{Discussion}

A significant reduction in the prevalence of anemia and increase in the mean hemoglobin concentration were found after supplementation in cycles (Cyclical Group). This occurred with two short periods of daily iron administration; both the duration (20 days) of supplementation and the medication dose were smaller than reported in other studies $[7,8,17]$.

Likewise, for the group that received weekly supplementation (Weekly Group), a significant reduction in the prevalence of anemia and increase in mean hemoglobin concentration resulting from a proportionally lower weekly dosage of iron compared to that of other studies employing the same procedure was observed $[7,8,17]$.

Both approaches in the present study reduced the side effects associated to the ingestion of elemental iron compared to the administration of high dosages or longer periods of supplementation $[7,8,17]$. This reduction favored high compliance and no children left the study due to the treatment itself.

Regarding the feasibility of the two strategies, the staff members of the daycare centers reported greater difficulty in administering and managing the medication in the weekly group. When children missed daycare, their absence was recorded on individual charts, and the staff

\begin{tabular}{|c|c|c|c|c|c|c|}
\hline \multirow[t]{2}{*}{ Group } & \multicolumn{2}{|c|}{ Anemia (\%) } & \multicolumn{4}{|c|}{ Hemoglobin (g/dL) } \\
\hline & Initial & $\overline{\text { Final }}$ & Initial & Final & Change & $\mathrm{p}$-value \\
\hline $\begin{array}{l}\text { The } \\
\text { Weekly } \\
\text { Group } \\
(n=51)\end{array}$ & 17.65 & 3.92 & $11.75 \pm 0.76$ & $12.02 \pm 0.72$ & $0.27 \pm 0.77$ & $=0.016$ \\
\hline $\begin{array}{l}\text { The } \\
\text { Cyclical } \\
\text { Group } \\
(n=48)\end{array}$ & 22.90 & 6.25 & $11.66 \pm 0.91$ & $12.13 \pm 0.89$ & $0.47 \pm 0.72$ & $<0.0005$ \\
\hline
\end{tabular}

Data shown as means \pm standard deviation. 
members were careful to administer the missing dose on the day of the child's return.

According to the daycare staff, it was easier and less time-consuming to manage the group submitted to cyclical supplementation. On their return after absence from daycare, these children received normal medication and then continued to receive the missed doses at the end of the supplementation until 20 doses of iron supplementation had been administered. As this strategy only involved two cycles, extra medication was only needed twice throughout the ten months of intervention.

Iron supplementation is the choice treatment for populations with high prevalence of anemia [1]. According to previous studies, iron deficiency is the main cause of anemia in preschoolers $[7,8,11,13,17,18]$. Because our goal was to assess the reduction in the prevalence of anemia, the blood hemoglobin concentration was chosen as the laboratory test $[11,13,18]$. It is important to remember that iron deficiency is not the only cause of anemia and so iron supplementation will not resolve all cases.

The strategy proposed in this study involved short periods of daily supplementation repeated at intervals based on the mean life of red blood cells which is approximately 120 days [15]. We assessed the efficacy of this alternative procedure by comparing it with intermittent supplementation (weekly). Several previous publications report on the positive results of the weekly approach $[7,8,13,17,18]$.

This study has indicated that the supplementation in cycles significantly reduces the prevalence of anemia in preschoolers. One limitation of this study, as in most clinical trials, is that the researchers are more able to control the behavior of participants and so compliance tends to be much better than in everyday situations. However this does not invalidate the results of the study as the comparisons made here are with other studies and the authors believe that this technique of cyclical supplementation will improve overall compliance.

\section{Conclusion}

Both regimens significantly reduced the prevalence of anemia among preschoolers, but the findings reveal cyclical supplementation was easier to administer and control. Therefore, cyclical iron supplementation represents a new strategy to control anemia among preschoolers. Further studies can help assess the use of this strategy in larger populations and in a non-supervised setting would be of great interest.

\section{Competing interests}

The authors declare that there is no competing of interests.

\section{Authors' contributions}

GGPLC contributed to the study design, the fieldwork, data collection, interpretation of results, drafting of the manuscript, writing and editing it. PMC contributed to the study design, statistical analysis, interpretation of data and drafting of the manuscript, writing and editing it. JAC contributed to the study design, statistical analysis, interpreted the results and drafting of the manuscript. All authors read and approved the final manuscript.

\section{Acknowledgements}

We would like to thank the Administration of the city of Bady Bassitt and all the children and mothers who participated in this study.

\section{Funding}

This study received financial support from the Administration of the city of Bady Bassitt, Brazil. All the examinations, medication, access to playschools and the help of their staff were provided by the town council.

\section{Author details}

${ }^{1}$ Department of Post graduation, School of Medicine, São José do Rio Preto, São Paulo 15090-000, Brazil. ²Department of Pathology and Forensic Medicine, School of Medicine, São José do Rio Preto, São Paulo 15090-000, Brazil. ${ }^{3}$ Department of Epidemiology and Statistical Analysis, School of Medicine, São José do Rio Preto, São Paulo 15090-000, Brazil. Departamento de pós-graduação, Faculdade de Medicina de São José do Rio Preto, Av. Brigadeiro Faria Lima, 5416 ZIP 15090-000, São José do Rio Preto, SP, Brazil.

Received: 16 March 2012 Accepted: 27 December 2012

Published: 10 January 2013

\section{References}

1. Worldwide prevalence of anaemia 1993-2005. In WHO global database on anaemia. Edited by de Benoist B, McLean E, Egli I, Cogswell M. Geneva: WHO; 2008.

2. World Health Organization and the United Nations children's Fund: Focusing on anaemia. Towards an integrated approach for effective anaemia control. Geneva: WHO; 2004.

3. Ferraz IS, Daneluzzi JC, Vannucchi H, Jordão AA Jr, Ricco RG, Del Ciampo LA, et al: Prevalência da carência de ferro e sua associação com a deficiência de vitamina A em pré-escolares. J Pediatr (Rio J) 2005, 81(2):169-174. Porto Alegre mar./abr.

4. Vieira ACF, Diniz AS, Cabral PC, Oliveira RS, Lola MMF, Silva SMM, et al: Nutritional assessment of iron status and anemia in children under 5 years old at public day care centers. J Pediatr (Rio J) 2007, 83(4):370-376.

5. Assunção MC, Santos IS, Barros AJ, Gigante DP, Vitora CG: Effect of iron fortification of flour on anemia in preschool children in Pelotas. 41 st edition. Brazil: Rev Saude Publica; 2007:539-548.

6. ACC/SCN: United Nations Administrative Committee on Coordination/SubCommittee on Nutrition). Controlling iron deficiency. Geneva: ACC/SCN; 1991. Nutrition Policy Discussion, Paper 9.

7. Liu X, Kang J, Zhao L, Viteri FE: Intermittent iron supplementation is efficient and safe in controlling iron deficiency and anaemia in preschool children. Food Nutr Bulletin. 1995, 16:139-145.

8. Faqih AM, Kakish SB, Izzat M: Effectiveness of intermittent iron treatment of two-to six-year-old Jordanian children with iron-deficiency anemia. Food Nutr Bull 2006, 27(3):220-227.

9. Thu BD, Schultink W, Dillon D, Gross R, Leswara ND, Khoi HH: Effect of daily and weekly micronutrient supplementation on micronutrient deficiencies and growth in young Vietnamese children. Am J Clin Nutr 1999, 69:80-86.

10. Engstrom EM, de Castro IR, Portela M, Cardoso LO, Monteiro CA: Effectiveness of daily and weekly iron supplementation in the prevention of anemia in infants. 42nd edition. São Paulo: Rev. Saúde Pública; 2008. Available at http://www.scielo.br/scielo.php?script=sci_arttext\&pid=S0034$89102008000500002 \&$ lng=pt\&nrm=iso accessed on 18 out. 2012. Epub 08-Ago-2008. http://dx.doi.org/10.1590/S0034-89102008005000043.

11. Monteiro CA, Szarfarc SC, Brunken GS, Gross R, Conde WL: Long-term preventive mass prescription of weekly doses of iron sulfate may be highly effective to reduce endemic child anemia. Food Nutr Bulletin. 2001, 22:53-61.

12. Ferreira MU, Da Silva-Nunes M, Bertolino CN, Malafronte RS, Muniz PT, Cardoso MA: Anemia and iron deficiency in school children, adolescents and adults: A community-based study in rural Amazônia. Am J Public Health 2007, 97:237-239.

13. Coutinho GGPL, Goloni-Bertollo EM, Bertelli ECP: Effectiveness of two programs of intermittent ferrous supplementation for treating iron- 
deficiency anemia in infants: randomized clinical trial. Sao Paulo Med J 2008, 126(6):314-318.

14. Walter T, de Andraca I, Chadud P, Perales CG: Iron deficiency anemia: adverse effects on infant psychomotor development. Pediatrics 1989, 84:7-17.

15. Ganz T: Molecular control of iron transport. J Am Soc Nephrol 2007, 18:394-400.

16. International Nutritional Consultative Group (INACG): Measurements of iron status. Washington: INACG; 1985.

17. Schultink WJ, Gross R, Gliwitzki M, Karyadi D, Matulessi P: Effect of daily vs. twice weekly iron supplementation in Indonesian preschool children with low iron status. Am J Clin Nutr 1995, 61:111-115.

18. Palupi L, Schultink W, Achadi E, Gross R: Effective community intervention to improve hemoglobin status in preschoolers receiving once-weekly iron supplementation. Am J Clin Nutr 1997, 65:1057-1061.

doi:10.1186/1471-2458-13-21

Cite this article as: Coutinho et al:: Cyclical iron supplementation to reduce anemia among Brazilian preschoolers: a randomized controlled trial. BMC Public Health 2013 13:21.

\section{Submit your next manuscript to BioMed Central and take full advantage of:}

- Convenient online submission

- Thorough peer review

- No space constraints or color figure charges

- Immediate publication on acceptance

- Inclusion in PubMed, CAS, Scopus and Google Scholar

- Research which is freely available for redistribution 